\title{
Radiobiological modeling of two stereotactic body radiotherapy schedules in patients with stage I peripheral non-small cell lung cancer
}

\author{
Bao-tian Huang ${ }^{1}$, Zhu Lin ${ }^{1}$, Pei-xian Lin ${ }^{2}$, Jia-yang Lu', Chuang-zhen Chen ${ }^{1}$ \\ ${ }^{1}$ Department of Radiation Oncology, Cancer Hospital of Shantou University Medical College, Shantou 515031, China \\ ${ }^{2}$ Department of Nosocomial Infection Management, The Second Affiliated Hospital of Shantou University Medical College, \\ Shantou 515041, China \\ Correspondence to: Chuang-zhen Chen, email: stccz@139.com \\ Jia-yang Lu, email: tianjia2025@163.com
}

Keywords: radiobiological modeling, dose schedule, stereotactic body radiotherapy, non-small cell lung cancer

Received: December 11, $2015 \quad$ Accepted: April 18, $2016 \quad$ Published: May 18, 2016

\section{ABSTRACT}

This study aims to compare the radiobiological response of two stereotactic body radiotherapy (SBRT) schedules for patients with stage I peripheral non-small cell lung cancer (NSCLC) using radiobiological modeling methods. Volumetric modulated arc therapy (VMAT)-based SBRT plans were designed using two dose schedules of $1 \times 34 \mathrm{~Gy}$ ( $34 \mathrm{~Gy}$ in 1 fraction) and $4 \times 12 \mathrm{~Gy}$ (48 Gy in 4 fractions) for 19 patients diagnosed with primary stage I NSCLC. Dose to the gross target volume (GTV), planning target volume (PTV), lung and chest wall (CW) were converted to biologically equivalent dose in $2 \mathrm{~Gy}$ fraction $\left(E \mathrm{ED}_{2}\right)$ for comparison. Five different radiobiological models were employed to predict the tumor control probability (TCP) value. Three additional models were utilized to estimate the normal tissue complication probability (NTCP) value for the lung and the modified equivalent uniform dose (mEUD) value to the $\mathrm{CW}$. Our result indicates that the $1 \times 34 \mathrm{~Gy}$ dose schedule provided a higher $E Q D D_{2}$ dose to the tumor, lung and $C W$. Radiobiological modeling revealed that the TCP value for the tumor, NTCP value for the lung and mEUD value for the CW were $7.4 \%$ (in absolute value), $7.2 \%$ (in absolute value) and $71.8 \%$ (in relative value) higher on average, respectively, using the $1 \times 34$ Gy dose schedule.

\section{INTRODUCTION}

Stereotactic body radiation therapy (SBRT) is an effective and well-tolerated noninvasive treatment for patients with medically inoperable non-small cell lung cancer (NSCLC) [1-3]. Results from recent investigations demonstrate that SBRT treatment for early stage lung cancer can achieve outcomes comparable with surgical resection [4-6].

Although SBRT treatment for NSCLC has offered encouraging outcomes, investigations into the benefits of single and multiple dose schedules remain ongoing $[7,8]$. To date, there are no clinical results comparing the outcomes between single and multiple fraction schedules; thus, the problem requires further investigation.

Radiobiological modeling is a method used to simulate the treatment outcome of the tumor and normal tissues using mathematical calculations with parameters generated from fitting the clinical trials. This method has the advantage of linking the dosimetric variation with radiobiological responses and was recently used to predict the feasibility of dose escalation for esophageal cancer and primary prostate cancer $[9,10]$.

Therefore, the study mainly aims to compare the dose response between single and multiple fraction SBRT dose schedules in terms of tumor control probability (TCP) and normal tissue complication probability (NTCP) using the method of radiobiological modeling. Given that a dose of $34 \mathrm{~Gy}$ in a single fraction [11] and $48 \mathrm{~Gy}$ in four fractions [12-14] stand as the maximal and the most widely used dose schedules, respectively, it is important to demonstrate their feasibility, safety, and efficacy. Thus, these two fractionation schemes are worthy of comparison in this study. 


\section{RESULTS}

\section{Patient characteristics}

The patients' characteristics are listed in Table 1. In total, 14 of the patients suffered from $\mathrm{T} 1$ lesions and 5 of them suffered from T2 lesions. The median volume of gross target volume (GTV) and planning target volume (PTV) were $8.8 \pm 10.4$ and $36.9 \pm 24.9 \mathrm{~cm}^{3}$, respectively.

\section{Dose comparison between the $1 \times 34 \mathrm{~Gy}$ and $4 \times 12$ Gy dose schedule}

Dose to the GTV, PTV-GTV (PTV minus GTV), lung and chest wall $(\mathrm{CW})$ between the two dose schedules after conversion to biologically equivalent dose in $2 \mathrm{~Gy}$ fractions $\left(\mathrm{EQD}_{2}\right)$ were listed in Table 2. All the dose comparisons were statistically significant with $p$-values $<0.05$. Specifically, the $1 \times 34$ Gy schedule provided up to $47.1 \%$ and $44.1 \%$ higher dose on average for the GTV and PTV-GTV, respectively. Moreover, the $1 \times 34$ Gy schedule also added 3.1-7.9\% more dose on average to $\mathrm{V}_{10}-\mathrm{V}_{60}$ of the $\mathrm{CW}$. However, the dose delivered to the lung was much smaller, with $\mathrm{V}_{5}-\mathrm{V}_{70}$ increasing by $1.0-2.2 \%$. The cumulative dose volume histogram $(\mathrm{cDVH})$ of the GTV, PTV-GTV, lung and CW after $\mathrm{EQD}_{2}$ dose conversion is presented in Figure 1. Dose distributions from the transversal, coronal and sagittal views are presented in Figure 2.

\section{Dose response between the $1 \times 34 \mathrm{~Gy}$ and $4 \times 12$ Gy dose schedule}

By radiobiological modeling, we found that five TCP and two lung complication predicting models yielded similar results. Radiobiological modeling revealed that TCP value for the tumor and NTCP value for the lung were $7.4 \%$ and $7.2 \%$ higher (in absolute value), respectively, on average with the $1 \times 34$ Gy schedule compared with the $4 \times 12$ Gy schedule. The modified equivalent uniform dose (mEUD) value to the $\mathrm{CW}$ was also increased by $71.8 \%$ in relative value. Detailed information of TCP prediction in the five models is presented in Table 3. Data regarding the NTCP for the lung and mEUD value to the CW between the two dose schedules are provided in Table 4.

\section{DISCUSSION}

Our analysis of the dose response for stage I NSCLC using radiobiological modeling revealed that the TCP value for the tumor was $7.4 \%$ higher with the $1 \times 34$ Gy dose schedule. In addition, the NTCP value for the lung and mEUD value to the $\mathrm{CW}$ were increased by $7.2 \%$ in absolute value and $71.8 \%$ in relative value on average, respectively, compared with the $4 \times 12$ Gy schedule. To our knowledge, our study is the first to use different radiobiological models to predict TCP and NTCP data in single and multiple fraction dose schedules. We believe that our results can provide useful information for clinical SBRT treatment of lung lesion.

The incidence of radiation pneumonitis (RP) ranges from $10 \%$ to $20.3 \%$ [15-17], and the median intervals to first graphical appearance were 4.2 and 2.5 months for grade 1 and grade $2-3 \mathrm{RP}$, respectively [18]. Similarly, the incidence of $\mathrm{CW}$ toxicity ranged from $8.3 \%$ to $32.8 \%$ [19-23] and frequently occurred greater than 6 months after the completion of therapy [23]. As the RP and CW pain are common radiotherapy-induced side effects for peripheral NSCLC patients undergoing SBRT, our study mainly focuses on predicting the complication probability of the lung and CW between the two dose schedules.

The $1 \times 34$ Gy and $4 \times 12$ Gy dose schedules have been widely used in SBRT treatment for lung cancer and many publications have reported their feasibility, safety and efficacy in clinical treatment. Hara et al reported that irradiation doses of $\geq 30$ Gy resulted in 1-year local progression-free rates (LPFRs) of 93\% in fifty tumors and Grade 3 respiratory symptoms were only noted in 1 patient [11]. Videtic et al observed 1-year local control of $86.2 \%$ and no grade 3 or higher toxicity with the $1 \times 34$ Gy schedule [24]. Nagata et al observed that $98 \%$ of 45 tumors were locally controlled during the followup period, and no pulmonary complications greater than Grade 3 were noted with the $4 \times 12$ Gy scheme [12]. Kelley et al reported $81.8 \%$ local control at one year for the entire cohort and no grade 3 or greater toxicity adverse events were observed with the $4 \times 12$ Gy scheme for treatment of medically inoperable NSCLC patients [13]. The mentioned outcomes demonstrate comparable local control and incidences of adverse events between the two dose schedules. However, our finding that the TCP for the tumor and the risk of radiation-induced complication were higher with the $1 \times 34$ Gy schedule slightly differs from the results of these studies. Given that the study was comparing the TCP and NTCP using two schedules of prescription dose, it is not suitable to compare this study using radiobiological modeling with the clinical data of the previous study. How to better fit to clinical data with radiobiological models will be a subject of our future work.

The repopulation and reoxygenation in tumor cells are two problematic factors that should be taken into account during the radiobiological modeling of single and multiple fraction schedules. Single-fraction SBRT is a promising modality that has the potential to circumvent the problem of repopulation, which can occur during conventional, fractionated radiation therapy [11]. The impact of tumor cell repopulation could be ignored when accelerated repopulation was observed in less than 21 days [25], as noted in lung SBRT treatment. Regarding tumor reoxygenation, multiple fraction schedules are more beneficial for hypoxic tumors, as 
Table 1: Characteristics of 19 patients with NSCLC undergoing SBRT

\begin{tabular}{|c|c|c|c|c|c|}
\hline Patient & Gender & Age & Stage* & GTV $\left(\mathrm{cm}^{3}\right)$ & PTV $\left(\mathrm{cm}^{3}\right)$ \\
\hline 1 & $\mathrm{~F}$ & 57 & $\mathrm{~T} 1$ & 0.9 & 8.1 \\
\hline 2 & M & 35 & $\mathrm{~T} 1$ & 1.0 & 9.8 \\
\hline 3 & $\mathrm{~F}$ & 55 & $\mathrm{~T} 1$ & 2.1 & 20.2 \\
\hline 4 & $\mathrm{M}$ & 71 & $\mathrm{~T} 1$ & 3.1 & 16.3 \\
\hline 5 & M & 64 & $\mathrm{~T} 1$ & 3.3 & 23.0 \\
\hline 6 & M & 62 & $\mathrm{~T} 1$ & 3.4 & 20.0 \\
\hline 7 & M & 68 & $\mathrm{~T} 1$ & 3.6 & 27.6 \\
\hline 8 & $\mathrm{~F}$ & 59 & $\mathrm{~T} 1$ & 4.0 & 32.9 \\
\hline 9 & $\mathrm{~F}$ & 76 & $\mathrm{~T} 1$ & 4.2 & 23.2 \\
\hline 10 & M & 68 & $\mathrm{~T} 1$ & 4.3 & 22.4 \\
\hline 11 & $\mathrm{~F}$ & 63 & $\mathrm{~T} 1$ & 4.6 & 39.9 \\
\hline 12 & $\mathrm{~F}$ & 72 & $\mathrm{~T} 1$ & 5.4 & 31.3 \\
\hline 13 & $\mathrm{~F}$ & 71 & $\mathrm{~T} 1$ & 6.9 & 28.7 \\
\hline 14 & $\mathrm{~F}$ & 62 & $\mathrm{~T} 1$ & 9.7 & 63.5 \\
\hline 15 & $\mathrm{~F}$ & 70 & $\mathrm{~T} 2$ & 10.3 & 39.5 \\
\hline 16 & M & 70 & $\mathrm{~T} 2$ & 11.6 & 40.8 \\
\hline 17 & $\mathrm{M}$ & 72 & $\mathrm{~T} 2$ & 21.0 & 71.0 \\
\hline 18 & M & 77 & $\mathrm{~T} 2$ & 26.7 & 95.1 \\
\hline 19 & $\mathrm{M}$ & 48 & $\mathrm{~T} 2$ & 41.6 & 87.9 \\
\hline
\end{tabular}

Abbreviations: GTV = gross target volume; PTV = planning target volume;

$\mathrm{M}=$ Male; $\mathrm{F}=$ Female;

Note: *According to American Joint Committee on Cancer (AJCC), 7th edition.

noted in lung tumors. However, the impact of interfraction fast reoxygenation of the hypoxic cells remains unclear, particularly in small fraction SBRT treatment. The recent investigation demonstrated a reduction in $\mathrm{D}_{50}$ from 53.3 Gy for 2 fractions to 52.7 Gy for 5 fractions for hypofractionated treatments employing large doses per fraction due to a synergistic effect between intra-fraction repair and inter-fraction fast reoxygenation of the hypoxic cells [26]. The results indicated a slight impact of tumor cells' reoxygenation in less than 5 fractions of treatment. In summary, we believe the impact of repopulation and reoxygenation of the tumor cells on radiobiological modeling is negligible because our study only includes 1 and 4 fraction dose schedules.

The EQD 2 conversion in the present study was performed using the linear-quadratic (LQ) model that is derived from biological considerations of how cells could be killed by ionizing radiation [27]. The suitability of the LQ model for high doses has been intensely debated in recent years. Recently, increasing clinical evidence has confirmed the accuracy of LQ-based tumor control and normal tissue predicting models. Guckenberger et al suggested that the traditional LQ formalism is accurately modeled for stage I NSCLC patients undergoing fractionated SBRT based on 395 patients from 13 German and Austrian centers [28]. Shuryak et al also found that LQ-based TCP models can provide significantly better fits to single-fraction local control data for SBRT treatment of NSCLC compared with other models requiring extra terms at high doses [29]. Borst et al demonstrated that the LQ model was valid for estimating the toxicity probabilities of RP [30]. According to two clinical studies, we believe that the dose conversion in our study utilizing the LQ model is reliable.

The results of our analysis are dependent on the choice of radiobiological models and parameters used. Therefore, we used a series of models from the literature to confirm our result. Five TCP predicting models were used in the present study and the radiobiological parameters of four models were derived from clinical data. Particularly, the Nitin model was generated by retrospectively analyzing 504 NSCLC tumors treated 
A

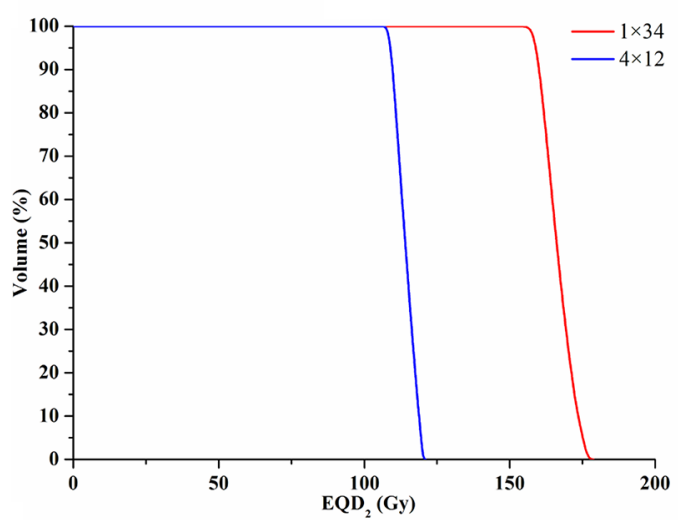

C

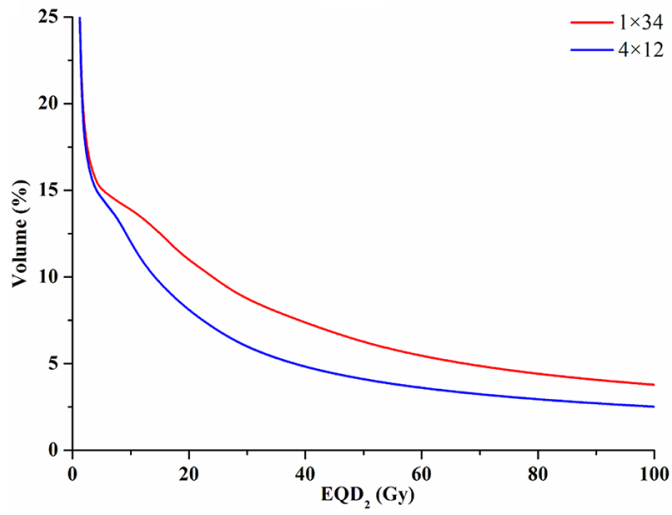

B

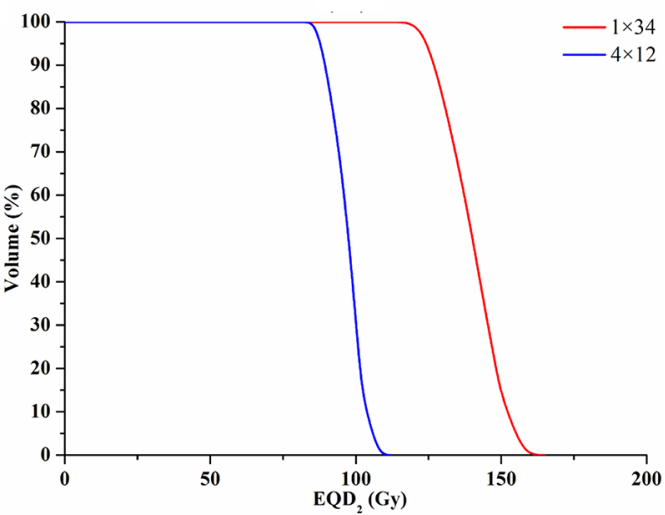

D

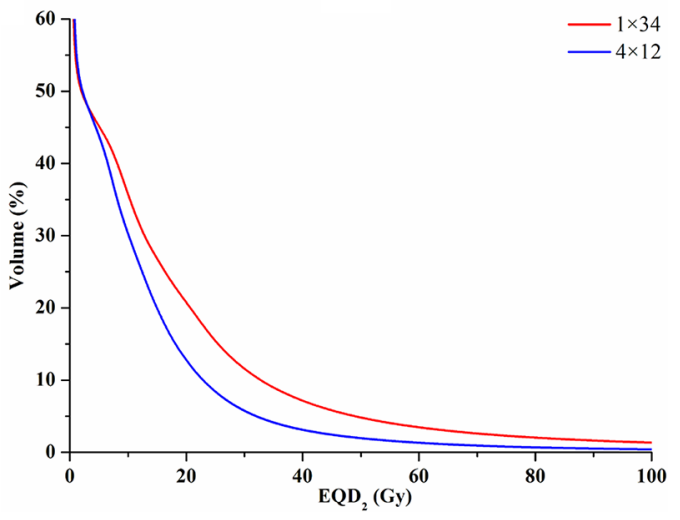

Figure 1: DVH of the GTV, PTV-GTV, lung and CW after EQD ${ }_{2}$ conversion. (A) DVH of the GTV, (B) DVH of the PTV-GTV, (C) DVH of the lung, and (D) DVH of the CW. GTV = gross target volume; PTV = planning target volume; PTV-GTV = PTV minus GTV; $\mathrm{CW}=$ chest wall; $\mathrm{EQD}_{2}=$ biologically equivalent dose in $2 \mathrm{~Gy}$ fractions.

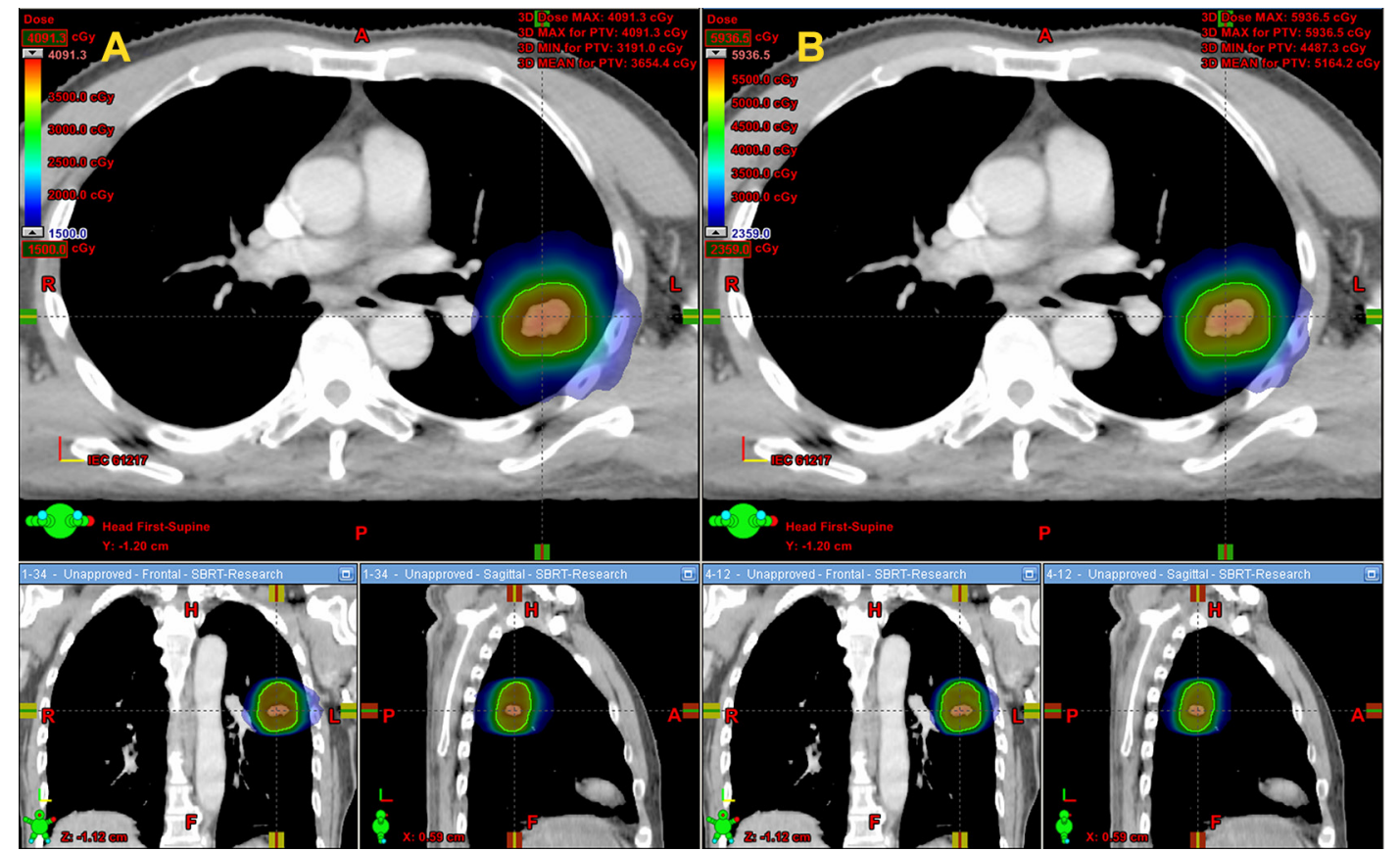

Figure 2: Dose distribution from the transversal, coronal and sagittal views between the two dose schedules. The dose color wash slider was set at $15 \mathrm{~Gy}$ for the $1 \times 34 \mathrm{~Gy}$ schedule and $23.59 \mathrm{~Gy}$ for the $4 \times 12 \mathrm{~Gy}$ schedule (the same $\mathrm{EQD}_{2}$ dose). (A) Dose distribution of the $1 \times 34$ Gy schedule. (B) Dose distribution of the $4 \times 12$ Gy schedule. 
Table 2: EQD dose comparison between $1 \times 34 \mathrm{~Gy}$ and $4 \times 12 \mathrm{~Gy}$ dose schedules

\begin{tabular}{|c|c|c|c|c|}
\hline Structures & Parameter & $1 \times 34$ Gy & $4 \times 12$ Gy & $p$ \\
\hline GTV & $\mathrm{D}_{\text {mean }}(\mathrm{Gy})$ & $167.6 \pm 6.0$ & $113.9 \pm 3.5$ & 0.000 \\
\hline PTV-GTV & $\mathrm{D}_{\text {mean }}(\mathrm{Gy})$ & $140.9 \pm 2.8$ & $97.8 \pm 1.7$ & 0.000 \\
\hline \multirow{9}{*}{ Lung } & $\mathrm{V}_{5}(\%)$ & $13.9 \pm 5.0$ & $12.9 \pm 4.9$ & 0.000 \\
\hline & $\mathrm{V}_{10}(\%)$ & $11.9 \pm 4.7$ & $10.4 \pm 4.5$ & 0.000 \\
\hline & $\mathrm{V}_{20}(\%)$ & $9.4 \pm 4.0$ & $7.2 \pm 3.3$ & 0.000 \\
\hline & $\mathrm{V}_{30}(\%)$ & $7.7 \pm 3.4$ & $5.5 \pm 2.7$ & 0.000 \\
\hline & $\mathrm{V}_{40}(\%)$ & $6.4 \pm 3.0$ & $4.4 \pm 2.2$ & 0.000 \\
\hline & $\mathrm{V}_{50}(\%)$ & $5.6 \pm 2.7$ & $3.6 \pm 1.9$ & 0.000 \\
\hline & $\mathrm{V}_{60}(\%)$ & $4.9 \pm 2.4$ & $3.1 \pm 1.6$ & 0.000 \\
\hline & $\mathrm{V}_{70}(\%)$ & $4.4 \pm 2.2$ & $2.7 \pm 1.4$ & 0.000 \\
\hline & $\mathrm{D}_{\text {mean }}(\mathrm{Gy})$ & $12.4 \pm 7.3$ & $7.0 \pm 3.6$ & 0.000 \\
\hline \multirow{7}{*}{$\mathrm{CW}$} & $\mathrm{V}_{10}(\%)$ & $39.2 \pm 12.1$ & $34.7 \pm 12.1$ & 0.000 \\
\hline & $\mathrm{V}_{20}(\%)$ & $25.6 \pm 11.1$ & $17.7 \pm 8.6$ & 0.000 \\
\hline & $\mathrm{V}_{30}(\%)$ & $16.5 \pm 8.0$ & $8.6 \pm 5.2$ & 0.000 \\
\hline & $\mathrm{V}_{40}(\%)$ & $10.7 \pm 5.8$ & $4.6 \pm 3.8$ & 0.000 \\
\hline & $\mathrm{V}_{50}(\%)$ & $7.1 \pm 4.7$ & $2.8 \pm 2.7$ & 0.000 \\
\hline & $\mathrm{V}_{60}(\%)$ & $5.0 \pm 3.9$ & $1.9 \pm 2.0$ & 0.000 \\
\hline & $\mathrm{D}_{\text {mean }}(\mathrm{Gy})$ & $24.8 \pm 10.4$ & $15.3 \pm 5.6$ & 0.000 \\
\hline
\end{tabular}

Abbreviations: GTV = gross target volume; PTV = planning target volume; PTV-GTV = PTV minus GTV. CW = chest wall; $\mathrm{D}_{\text {mean }}=$ mean dose; $\mathrm{V}_{\mathrm{x}}$ was the volume of the organ receiving a dose of $\mathrm{x}$ Gy or more.

Table 3: TCP value between $1 \times 34 \mathrm{~Gy}$ and $4 \times 12 \mathrm{~Gy}$ dose schedule in five models

\begin{tabular}{|c|c|c|c|}
\hline Parameter & $1 \times 34$ Gy & $4 \times 12$ Gy & $p$ \\
\hline Mar (\%) & $98.3 \pm 0.4$ & $85.3 \pm 2.5$ & 0.000 \\
\hline Fen $(\%)^{*}$ & $95.8 \pm 1.3$ & $90.9 \pm 3.5$ & 0.000 \\
\hline WN (\%) & $94.3 \pm 0.7$ & $85.5 \pm 2.0$ & 0.000 \\
\hline EUD (\%) & $98.1 \pm 0.2$ & $93.4 \pm 0.7$ & 0.000 \\
\hline Nitin (\%) & $98.1 \pm 0.7$ & $92.6 \pm 2.4$ & 0.000 \\
\hline Median (\%) & $96.9 \pm 1.7$ & $89.5 \pm 4.2$ & 0.000 \\
\hline
\end{tabular}

Abbreviations: Mar = Martel model; Fen $=$ Fenwick model; $W N=$ Webb-Nahum model; EUD $=$ equivalent uniform dose model; Nitin = Nitin model.

Note: *Indicates Fenwick model for TCP prediction.

with a variety of SBRT schedules [31]. Interestingly, different radiobiological models predicted similar trends, irrespective of the TCP or NTCP prediction, suggesting their feasibility in predicting the radiobiological response.

Although our study has predicted the dose response of $1 \times 34$ Gy and $4 \times 12$ Gy schedules, our study has some limitations. (1) Our analysis is mainly based on radiobiological modeling and the results should be confirmed in large prospective, randomized, controlled clinical trials. (2) We ignored the radiation-induced rib fracture in lung SBRT. Although several studies reported that the tumor-chest wall distance is a risk factor for rib 
Table 4: NTCP value for the lung and mEUD value for the CW between $1 \times 34 \mathrm{~Gy}$ and $4 \times 12 \mathrm{~Gy}$ dose schedules

\begin{tabular}{|c|c|c|c|}
\hline Parameter & $1 \times 34$ Gy & $4 \times 12 G y$ & $p$ \\
\hline \multicolumn{4}{|l|}{ Lung } \\
\hline LKB (\%) & $13.6 \pm 10.2$ & $5.8 \pm 3.0$ & 0.000 \\
\hline Fen $(\%)^{*}$ & $11.6 \pm 8.7$ & $4.9 \pm 2.5$ & 0.000 \\
\hline Median (\%) & $12.6 \pm 9.4$ & $5.4 \pm 2.8$ & 0.000 \\
\hline \multicolumn{4}{|l|}{$\mathrm{CW}$} \\
\hline mEUD (\%) & $175.1 \pm 89.1$ & $101.9 \pm 48.9$ & 0.000 \\
\hline
\end{tabular}

Abbreviations: LKB = Lyman-Kutcher-Burman (LKB) model; Fen = Fenwick model; mEUD = modified equivalent uniform dose model; $\mathrm{CW}=$ chest wall.

Note: "Indicates Fenwick model for NTCP estimation to the lung.

fracture [32], no radiobiological model has been proposed to predict the incidence of this condition; thus, we could not easily evaluate rib fracture during the modeling.

In conclusion, radiobiological modeling analysis demonstrates that the $1 \times 34$ Gy dose schedule achieves $7.4 \%$ higher TCP prediction but also increases radiationinduced lung and $\mathrm{CW}$ complication probabilities by $7.2 \%$ (absolute value) and $71.8 \%$ (relative value), respectively, compared with the $4 \times 12$ schedule.

\section{MATERIALS AND METHODS}

\section{Ethics statement}

The protocol was approved by the Ethics Committee of Cancer Hospital of Shantou University Medical College. Given that this is not a treatment-based study, our institutional review board waived the need for written informed consent from the participants. However, patient information was anonymous to protect their confidentiality.

\section{Patients selection}

Nineteen patients previously diagnosed with peripheral stage I primary NSCLC and treated with radiotherapy were used in this study. A peripheral lesion was defined as the tumor $>2 \mathrm{~cm}$ in all directions around the proximal bronchial tree according to the definition in Radiation Therapy Oncology Group (RTOG) 0915 report [33]. Meanwhile, the tumor must be beyond $1 \mathrm{~cm}$ of major vessels, esophagus, heart, trachea, pericardium, brachial plexus and vertebral bodies. Inclusion criteria in the study included (1) histological confirmation of NSCLC prior to treatment, (2) stage T1N0M0 or T2N0M0 (maximal diameter $\leq 5 \mathrm{~cm}$ in any direction), (3) age $>18$ years old.

\section{Computed tomography (CT) scanning}

The patients were simulated on a supine position with a vacuum bag (Medtec Medical, Inc. Buffalo Grove, IL) or a thermoplastic mask (Guangzhou Klarity Medical \& Equipment Co., Ltd, Guangzhou, China) restricting system. All of the patients underwent respiratory-correlated four dimensional computed tomography (4DCT) scans using Brilliance $\mathrm{CT}$ with Big Bore (Cleveland, OH, USA). CT images were obtained at a 3-mm slice thickness during scanning. CT images were then transferred to an Eclipse treatment planning system (Version 10.0, Varian Medical System, Inc., Palo Alto, CA) for target delineation, organs at risk (OARs) contouring and treatment planning.

\section{Delineation of target volume and OARs}

For target contouring, the internal target volume (ITV) was defined as the integration of the GTV on 10 phases of the 4DCT in the pulmonary windows. To account for set-up uncertainties and mechanical tolerance, a PTV was created by adding a uniform 5-mm margin expansion to the ITV. As to normal tissue contouring, the entire lung was limited to the air-inflated lung parenchyma, and the GTV and trachea/ipsilateral bronchus were excluded according to the RTOG 0915 report [33]. The CW was segmented from the corrected lung edges with a $20-\mathrm{mm}$ expansion in the lateral, anterior, and posterior directions, excluding the lung volume and the mediastinal soft tissue $[19,34,35]$. If the 20-mm expansion extended outside the body, the contour extended only as far as the external patient surface [35]. To avoid cumbersome contouring of the entire $\mathrm{CW}$, we defined the $\mathrm{CW}$ within a $30-\mathrm{mm}$ limit in the head-to-feet direction from the PTV [34]. 


\section{Treatment planning}

Two dose schedules of $1 \times 34$ Gy and $4 \times 12$ Gy were prescribed. The treatment plans were designed using the Eclipse treatment planning system and conducted on the averaged 4DCT. Treatment plans were designed using the volumetric modulated arc therapy (VMAT) technique. All plans were designed on a TrueBeam Linac with a $6 \mathrm{MV}$ flattening filter free (FFF) photon beam (maximum dose rate of $1400 \mathrm{MU} / \mathrm{min}$ ). Plans were created using dual partial arcs to prevent irradiation from entering the contralateral lung. The collimator angles for all plans were set to $30^{\circ}$ and $330^{\circ}$ to minimize the contribution of the tongue-and-groove effect to the dose. Optimization was performed using the progressive resolution optimizer (PRO_10028) algorithm implemented in Eclipse 10.0. Dose calculation was performed using the anisotropic analytical algorithm (AAA_10028) with a grid resolution of $1 \mathrm{~mm}$, considering the heterogeneity correction. The dose was normalized to $95 \%$ of the PTV receiving the prescribed dose. Prescription constraints, intermediate dose spillage and critical organ dose-volume limits in the two dose schedules were based on the criterion of the RTOG 0915 protocol [33]. Because RTOG 0915 report demands rapid dose fall-off beyond the target, the dose to the GTV was always greater than $120 \%$ of the prescribed dose.

\section{Dosimetric evaluation of the two dose schedules}

For clarification, all doses mentioned in the article were converted to the EQD 2 dose using the LQ model. The target was divided into two substructures of GTV and
PTV-GTV for comparison. For GTV and PTV-GTV, the evaluating parameter was the mean dose. For the lung and $\mathrm{CW}$, the analysis included the mean dose and a set of dose volume histogram (DVH)-based values. cDVH for the target and OARs were reconstructed from the individual DVH. These histograms were obtained by averaging the corresponding volumes for each dose bin of $0.05 \mathrm{~Gy}$. Dose distributions from the transversal, coronal and sagittal views between the two dose schedules were acquired at $15 \mathrm{~Gy}$ and $23.59 \mathrm{~Gy}$ (with the same EQD 2 dose) for the $1 \times 34$ Gy and $4 \times 12$ Gy schedules, respectively.

\section{Radiobiological modeling}

Both the TCP and NTCP were calculated using in-house developed programs using MATLAB 7.0 (MathWorks, USA). The TCP was calculated using five different radiobiological models, including the Martel model [36], Fenwick model [37], Webb-Nahum model [38], equivalent uniform dose (EUD) model [39] and Nitin model [31]. We utilized the EUD-based LymanKutcher-Burman (LKB) model [40] and Fenwick model [37] to estimate the NTCP for the lung. Radiation-induced CW toxicities were predicted for the 100-cc highest dose region using the mEUD model with moderate weighting [20]. A flow chart of the radiobiological modeling is presented in Figure 3. A detailed modeling procedure is described as follows: (1) cDVH statistics of GTV, lung and CW were imported into MATLAB software at a resolution of $0.05 \mathrm{~Gy}$. (2) Then, the cDVH statistics were converted to the differential dose volume histogram (dDVH) according to the method of Hiram [39]. (3) To reduce the effects of heterogeneity in the two dose

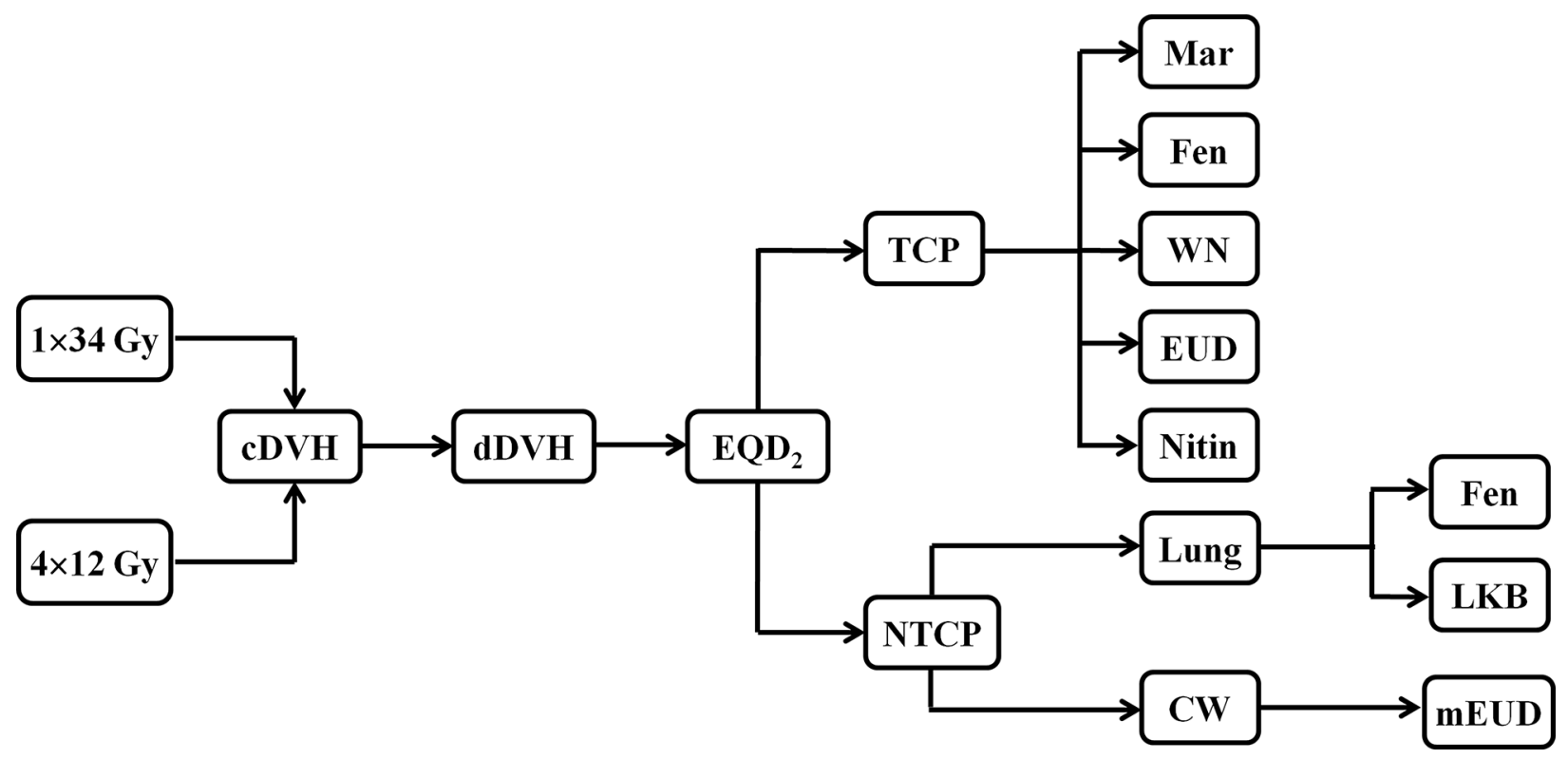

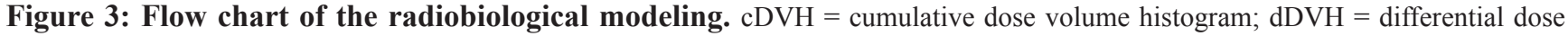
volume histogram; $\mathrm{EQD}_{2}=$ biologically equivalent dose in 2 Gy fractions; TCP = tumor control probability; NTCP $=$ normal tissue complication probability; Mar = Martel model; Fen = Fenwick model; WN = Webb-Nahum model; EUD = equivalent uniform dose model; Nitin = Nitin model; LKB $=$ Lyman-Kutcher-Burman $(L K B)$ model; mEUD $=$ modified equivalent uniform dose model; $\mathrm{CW}=$ chest wall . 
schedules, the program converted the dose in each volume element to an $\mathrm{EQD}_{2}$ dose using the formula reported by other publications [41, 42]. (4) Finally, the main program of different calculation models and the TCP and NTCP values were automatically calculated. An $\alpha / \beta$ value of 10 Gy was assigned for the tumor during the $\mathrm{EQD}_{2}$ conversion $[43,44] . \alpha / \beta$ values of $1.3 \mathrm{~Gy}$ and $3 \mathrm{~Gy}$ were assigned to estimate the NTCP for the lung and the MEUD value to the $\mathrm{CW}$, respectively $[25,45]$. Radiobiological parameters in the Martel, Fenwick, Nitin and mEUD models were obtained from the original work. Particularly, $\alpha_{\mathrm{m}}$ and $\sigma_{\mathrm{a}}$ values in the Webb-Nahum model were 0.30 and 0.1, respectively, by averaging 10 different histological subtypes of human lung cancer cell lines from Carmichael's report [46]. Cell density, $\rho$ was equal to $10^{8}$ according to Lindblom's work [47]. $\mathrm{TCD}_{50}$ and $\gamma_{50}$ parameters in the EUD model were obtained from Okunieff's work [48], and $\alpha$ was 0.30 according to Carmichael's report [46]. $\mathrm{TD}_{50}, \mathrm{n}$ and $\mathrm{m}$ in the LKB model were obtained from Seppenwoolde's result [49]. The larger the TCP, NTCP and mEUD values, the higher control rate for the tumor or higher incidence rate of complications in the lung and $\mathrm{CW}$.

\section{Statistical analysis}

Median values and standard deviation are reported in the study. The Statistical Package for Social Sciences (SPSS, version 19.0, Chicago, IL) was used for statistical analysis. Comparison of the DVH-based parameters was performed using paired, two-tailed Student's t-test. A Wilcoxon matched-pair signed-rank test was alternatively used when the data did not follow a normal distribution. The results were considered statistically significant when $p$-values $<0.05$.

\section{CONFLICTS OF INTEREST}

No conflicts of interest from all participating authors.

\section{GRANT SUPPORT}

This work was sponsored by Medical Scientific Research Foundation of Guangdong Province (A2015534), Shantou Medical Science and Technology Planning Project [Grant No. (2015)123], Shantou University Medical College Clinical Research Enhancement Initiative (201424), Collaborative and Creative Center, Molecular Diagnosis and Personalized Medicine, Shantou University, Guangdong Province, China.

\section{REFERENCES}

1. Xia T, Li H, Sun Q, Wang Y, Fan N, Yu Y, Li P, Chang JY. Promising clinical outcome of stereotactic body radiation therapy for patients with inoperable Stage I/II non-small-cell lung cancer. Int J Radiat Oncol Biol Phys. 2006; 66:117-125.
2. Baumann P, Nyman J, Hoyer M, Wennberg B, Gagliardi G, Lax I, Drugge N, Ekberg L, Friesland S, Johansson KA, Lund JA, Morhed E, Nilsson K, et al. Outcome in a prospective phase II trial of medically inoperable stage I non-small-cell lung cancer patients treated with stereotactic body radiotherapy. J Clin Oncol. 2009; 27:3290-3296.

3. Timmerman R, Paulus R, Galvin J, Michalski J, Straube W, Bradley J, Fakiris A, Bezjak A, Videtic G, Johnstone D, Fowler J, Gore E, Choy H. Stereotactic body radiation therapy for inoperable early stage lung cancer. JAMA. 2010; 303:1070-1076.

4. Solda F, Lodge M, Ashley S, Whitington A, Goldstraw P, Brada M. Stereotactic radiotherapy (SABR) for the treatment of primary non-small cell lung cancer; systematic review and comparison with a surgical cohort. Radiother Oncol. 2013; 109:1-7.

5. Zheng X, Schipper M, Kidwell K, Lin J, Reddy R, Ren Y, Chang A, Lv F, Orringer M, Spring Kong FM. Survival outcome after stereotactic body radiation therapy and surgery for stage I non-small cell lung cancer: a metaanalysis. Int J Radiat Oncol Biol Phys. 2014; 90:603-611.

6. Zhang B, Zhu F, Ma X, Tian Y, Cao D, Luo S, Xuan Y, Liu L, Wei Y. Matched-pair comparisons of stereotactic body radiotherapy (SBRT) versus surgery for the treatment of early stage non-small cell lung cancer: a systematic review and meta-analysis. Radiother Oncol. 2014; 112:250-255.

7. Stephans KL, Djemil T, Reddy CA, Gajdos SM, Kolar M, Mason D, Murthy S, Rice TW, Mazzone P, Machuzak M, Mekhail T, Videtic GM. A comparison of two stereotactic body radiation fractionation schedules for medically inoperable stage I non-small cell lung cancer: the Cleveland Clinic experience. J Thorac Oncol. 2009; 4:976-982.

8. Videtic GM, Hu C, Singh AK, Chang JY, Parker W, Olivier KR, Schild SE, Komaki R, Urbanic JJ, Choy H. A Randomized Phase 2 Study Comparing 2 Stereotactic Body Radiation Therapy Schedules for Medically Inoperable Patients With Stage I Peripheral Non-Small Cell Lung Cancer: NRG Oncology RTOG 0915 (NCCTG N0927). Int J Radiat Oncol Biol Phys. 2015; 93:757-764.

9. Warren S, Partridge M, Carrington R, Hurt C, Crosby T, Hawkins MA. Radiobiological determination of dose escalation and normal tissue toxicity in definitive chemoradiation therapy for esophageal cancer. Int J Radiat Oncol Biol Phys. 2014; 90:423-429.

10. Kuang Y, Wu L, Hirata E, Miyazaki K, Sato M, Kwee SA. Volumetric modulated arc therapy planning for primary prostate cancer with selective intraprostatic boost determined by $18 \mathrm{~F}$-choline PET/CT. Int J Radiat Oncol Biol Phys. 2015; 91:1017-1025.

11. Hara R, Itami J, Kondo T, Aruga T, Uno T, Sasano N, Ohnishi K, Kiyozuka M, Fuse M, Ito M, Naoi K, Kohno Y. Clinical outcomes of single-fraction stereotactic radiation therapy of lung tumors. Cancer. 2006; 106:1347-1352.

12. Nagata Y, Takayama K, Matsuo Y, Norihisa Y, Mizowaki T, Sakamoto T, Sakamoto M, Mitsumori M, Shibuya K, 
Araki N, Yano S, Hiraoka M. Clinical outcomes of a phase I/II study of 48 Gy of stereotactic body radiotherapy in 4 fractions for primary lung cancer using a stereotactic body frame. Int J Radiat Oncol Biol Phys. 2005; 63:1427-1431.

13. Kelley KD, Benninghoff DL, Stein JS, Li JZ, Byrnes RT, Potters L, Knisely JP, Zinkin HD. Medically inoperable peripheral lung cancer treated with stereotactic body radiation therapy. Radiat Oncol. 2015; 10:120.

14. Shibamoto Y, Hashizume C, Baba F, Ayakawa S, Miyakawa A, Murai T, Takaoka T, Hattori Y, Asai R. Stereotactic body radiotherapy using a radiobiology-based regimen for stage I non-small-cell lung cancer: five-year mature results. J Thorac Oncol. 2015; 10:960-964.

15. Bongers EM, Botticella A, Palma DA, Haasbeek CJ, Warner A, Verbakel WF, Slotman B, Ricardi U, Senan S. Predictive parameters of symptomatic radiation pneumonitis following stereotactic or hypofractionated radiotherapy delivered using volumetric modulated arcs. Radiother Oncol. 2013; 109:95-99.

16. Baker R, Han G, Sarangkasiri S, DeMarco M, Turke C, Stevens CW, Dilling TJ. Clinical and dosimetric predictors of radiation pneumonitis in a large series of patients treated with stereotactic body radiation therapy to the lung. Int $\mathrm{J}$ Radiat Oncol Biol Phys. 2013; 85:190-195.

17. Matsuo Y, Shibuya K, Nakamura M, Narabayashi M, Sakanaka K, Ueki N, Miyagi K, Norihisa Y, Mizowaki T, Nagata Y, Hiraoka M. Dose-volume metrics associated with radiation pneumonitis after stereotactic body radiation therapy for lung cancer. Int J Radiat Oncol Biol Phys. 2012; 83:e545-549.

18. Kanemoto A, Matsumoto Y, Sugita T. Timing and characteristics of radiation pneumonitis after stereotactic body radiotherapy for peripherally located stage I lung cancer. Int J Clin Oncol. 2015; 20:680-685.

19. Dunlap NE, Cai J, Biedermann GB, Yang W, Benedict SH, Sheng K, Schefter TE, Kavanagh BD, Larner JM. Chest wall volume receiving $>30$ Gy predicts risk of severe pain and/or rib fracture after lung stereotactic body radiotherapy. Int J Radiat Oncol Biol Phys. 2010; 76:796-801.

20. Woody NM, Videtic GM, Stephans KL, Djemil T, Kim Y, Xia P. Predicting chest wall pain from lung stereotactic body radiotherapy for different fractionation schemes. Int J Radiat Oncol Biol Phys. 2012; 83:427-434.

21. Stephans KL, Djemil T, Tendulkar RD, Robinson CG, Reddy CA, Videtic GM. Prediction of chest wall toxicity from lung stereotactic body radiotherapy (SBRT). Int J Radiat Oncol Biol Phys. 2012; 82:974-980.

22. Lagerwaard FJ, Haasbeek CJ, Smit EF, Slotman BJ, Senan S. Outcomes of risk-adapted fractionated stereotactic radiotherapy for stage I non-small-cell lung cancer. Int J Radiat Oncol Biol Phys. 2008; 70:685-692.

23. Creach KM, El Naqa I, Bradley JD, Olsen JR, Parikh PJ, Drzymala RE, Bloch C, Robinson CG. Dosimetric predictors of chest wall pain after lung stereotactic body radiotherapy. Radiother Oncol. 2012; 104:23-27.
24. Videtic GM, Stephans KL, Woody NM, Reddy CA, Zhuang T, Magnelli A, Djemil T. 30 Gy or 34 Gy? Comparing 2 single-fraction SBRT dose schedules for stage I medically inoperable non-small cell lung cancer. Int J Radiat Oncol Biol Phys. 2014; 90:203-208.

25. Fowler JF, Tome WA, Fenwick JD, Mehta MP. A challenge to traditional radiation oncology. Int J Radiat Oncol Biol Phys. 2004; 60:1241-1256.

26. Lindblom E, Dasu A, Toma-Dasu I. Optimal fractionation in radiotherapy for non-small cell lung cancer - a modelling approach. Acta Oncol. 2015:1-7.

27. Brown JM, Carlson DJ, Brenner DJ. The tumor radiobiology of SRS and SBRT: are more than the 5 Rs involved? Int J Radiat Oncol Biol Phys. 2014; 88:254-262.

28. Guckenberger M, Klement RJ, Allgauer M, Appold S, Dieckmann K, Ernst I, Ganswindt U, Holy R, Nestle U, Nevinny-Stickel M, Semrau S, Sterzing F, Wittig A, et al. Applicability of the linear-quadratic formalism for modeling local tumor control probability in high dose per fraction stereotactic body radiotherapy for early stage nonsmall cell lung cancer. Radiother Oncol. 2013; 109:13-20.

29. Shuryak I, Carlson DJ, Brown JM, Brenner DJ. Highdose and fractionation effects in stereotactic radiation therapy: Analysis of tumor control data from 2965 patients. Radiother Oncol. 2015; 115:327-334.

30. Borst GR, Ishikawa M, Nijkamp J, Hauptmann M, Shirato H, Bengua G, Onimaru R, de Josien Bois A, Lebesque JV, Sonke JJ. Radiation pneumonitis after hypofractionated radiotherapy: evaluation of the LQ(L) model and different dose parameters. Int J Radiat Oncol Biol Phys. 2010; 77:1596-1603.

31. Ohri N, Werner-Wasik M, Grills IS, Belderbos J, Hope A, Yan D, Kestin LL, Guckenberger M, Sonke JJ, Bissonnette JP, Xiao Y. Modeling local control after hypofractionated stereotactic body radiation therapy for stage I non-small cell lung cancer: a report from the elekta collaborative lung research group. Int J Radiat Oncol Biol Phys. 2012; 84:e379-384.

32. Nambu A, Onishi H, Aoki S, Tominaga L, Kuriyama K, Araya M, Saito R, Maehata Y, Komiyama T, Marino K, Koshiishi T, Sawada E, Araki T. Rib fracture after stereotactic radiotherapy for primary lung cancer: prevalence, degree of clinical symptoms, and risk factors. BMC Cancer. 2013; 13:68.

33. Radiation Therapy Oncology Group. A Randomized Phase II Study Comparing 2 Stereotactic Body Radiation Therapy (SBRT) Schedules for Medically Inoperable Patients with Stage I Peripheral Non-Small Cell Lung Cancer. 2012; http://www.rtog.org/ClinicalTrials/ProtocolTable/ StudyDetails.aspx?study $=0915$

34. Kong FM, Ritter T, Quint DJ, Senan S, Gaspar LE, Komaki RU, Hurkmans CW, Timmerman R, Bezjak A, Bradley JD, Movsas B, Marsh L, Okunieff P, et al. Consideration of dose limits for organs at risk of thoracic radiotherapy: atlas for lung, proximal bronchial tree, esophagus, spinal cord, ribs, 
and brachial plexus. Int J Radiat Oncol Biol Phys. 2011; 81:1442-1457.

35. Mutter RW, Liu F, Abreu A, Yorke E, Jackson A, Rosenzweig KE. Dose-volume parameters predict for the development of chest wall pain after stereotactic body radiation for lung cancer. Int J Radiat Oncol Biol Phys. 2012; 82:1783-1790.

36. Martel MK, Ten Haken RK, Hazuka MB, Kessler ML, Strawderman M, Turrisi AT, Lawrence TS, Fraass BA, Lichter AS. Estimation of tumor control probability model parameters from 3-D dose distributions of non-small cell lung cancer patients. Lung Cancer. 1999; 24:31-37.

37. Fenwick JD, Nahum AE, Malik ZI, Eswar CV, Hatton MQ, Laurence VM, Lester JF, Landau DB. Escalation and intensification of radiotherapy for stage III non-small cell lung cancer: opportunities for treatment improvement. Clin Oncol (R Coll Radiol). 2009; 21:343-360.

38. Webb S, Nahum AE. A model for calculating tumour control probability in radiotherapy including the effects of inhomogeneous distributions of dose and clonogenic cell density. Phys Med Biol. 1993; 38:653-666.

39. Gay HA, Niemierko A. A free program for calculating EUD-based NTCP and TCP in external beam radiotherapy. Phys Med. 2007; 23:115-125.

40. Luxton G, Keall PJ, King CR. A new formula for normal tissue complication probability (NTCP) as a function of equivalent uniform dose (EUD). Phys Med Biol. 2008; 53:23-36.

41. Partridge M, Ramos M, Sardaro A, Brada M. Dose escalation for non-small cell lung cancer: analysis and modelling of published literature. Radiother Oncol. 2011; 99:6-11.

42. van Baardwijk A, Tome WA, van Elmpt W, Bentzen SM, Reymen B, Wanders R, Houben R, Ollers M, Lambin P, De Ruysscher D. Is high-dose stereotactic body radiotherapy (SBRT) for stage I non-small cell lung cancer (NSCLC) overkill? A systematic review. Radiother Oncol. 2012; 105:145-149.
43. Koshy M, Malik R, Weichselbaum RR, Sher DJ. Increasing radiation therapy dose is associated with improved survival in patients undergoing stereotactic body radiation therapy for stage I non-small-cell lung cancer. Int J Radiat Oncol Biol Phys. 2015; 91:344-350.

44. Liu L, Bassano DA, Prasad SC, Hahn SS, Chung CT. The linear-quadratic model and fractionated stereotactic radiotherapy. Int J Radiat Oncol Biol Phys. 2003; 57:827-832.

45. Scheenstra AE, Rossi MM, Belderbos JS, Damen EM, Lebesque JV, Sonke JJ. Alpha/beta ratio for normal lung tissue as estimated from lung cancer patients treated with stereotactic body and conventionally fractionated radiation therapy. Int J Radiat Oncol Biol Phys. 2014; 88:224-228.

46. Carmichael J, Degraff WG, Gamson J, Russo D, Gazdar AF, Levitt ML, Minna JD, Mitchell JB. Radiation sensitivity of human lung cancer cell lines. Eur J Cancer Clin Oncol. 1989; 25:527-534.

47. Lindblom E, Antonovic L, Dasu A, Lax I, Wersall P, TomaDasu I. Treatment fractionation for stereotactic radiotherapy of lung tumours: a modelling study of the influence of chronic and acute hypoxia on tumour control probability. Radiat Oncol. 2014; 9:149.

48. Okunieff P, Morgan D, Niemierko A, Suit HD. Radiation dose-response of human tumors. Int J Radiat Oncol Biol Phys. 1995; 32:1227-1237.

49. Seppenwoolde Y, Lebesque JV, de Jaeger K, Belderbos JS, Boersma LJ, Schilstra C, Henning GT, Hayman JA, Martel MK, Ten Haken RK. Comparing different NTCP models that predict the incidence of radiation pneumonitis. Normal tissue complication probability. Int J Radiat Oncol Biol Phys. 2003; 55:724-735. 